\title{
TECHNOLOGY REVENUE MANAGEMENT SYSTEM FOR CUSTOMER GROUPS IN HOTELS
}

\author{
José Guadix, Pablo Cortés, Luis Onieva, Jesús Muñuzuri \\ University of Seville
}

November 2008

Send correspondence to José Guadix, University of Seville, The School of Industrial

Engineering, Camino de los Descubrimientos, s/n, Seville 41092 (Email:

guadix@esi.us.es). 


\begin{abstract}
This paper discusses revenue management; a technique that focuses on decision making that will maximize profit from the sale of perishable inventory units. New technologies management plays an important role in the development of revenue management techniques. Each new advance in technology management leads to more sophisticated revenue business capabilities. Today decision support revenue management systems and technologies management are crucial factors for the success of businesses in service industries. This paper addresses the specific case of customer groups in hotels.

The paper introduces a new decision support system that sets the revenue maximization criteria for a hotel. The system includes a set of forecasting demand methods for customers. It addresses a general case considering individual guests and customer groups. The system also incorporates deterministic and stochastic mathematical programming models that help to make the best decisions. The actual revenue depends upon which reservation system the hotel uses. A simulation engine makes a comparison between different heuristics of room inventory control: the results include performance indexes such as occupancy rate, efficiency rate, and yield; it compares results and chooses one of them. The system proves its suitability for actual cases by testing against actual data and thus becomes an innovative and efficient tool in the management of hotels' reservation systems.
\end{abstract}


TECHNOLOGY REVENUE MANAGEMENT SYSTEM FOR CUSTOMER GROUPS IN HOTELS

\section{INTRODUCTION}

There exists an increased interest in recent years in using revenue management techniques to maximize profitability in capacity-constrained situations. As businesses seek out revenue management techniques to squeeze profits from increasingly more efficient business processes, researchers respond to this need. In the past, different industries used most of the characteristics underlying this technique. Perishable firms, such as bakers, grocers, fresh fruit vendors, or theater managers regulated demand by varying prices during specific periods of time.

After the US Airline Deregulation Act in 1978, any airline could operate any route at any time with whatever fares they choose, point out Smith, Leimkuhler and Darrow (1992). These facts lead the scientific community to develop a new management approach called revenue management. Initially revenue management techniques assumed that passengers chose from one particular fare class, without movement to a lower fare if it became available. Companies adopted differentiated pricing in order to compete for price sensitive travelers, without giving up the revenue from their existing, full fare customers. Later by extending these techniques, it allows for passenger flexibility among fare classes. Bodily and Weatherford (1995) also consider overbooking and allow for passenger adjustments. Belobaba and Weatherford $\underline{(1996)}$ perform a comparison of various decision making rules incorporating passenger adjustments.

In this way, they define revenue management as the sale of the right inventory unit to the right customer at the right time. The research focuses on hotels' revenue 
management so hotels use this type of system to determine the number of available rooms at different rates (see Table 1 for a timeline review). Rothstein (1971) performed the early work on overbooking of hotel reservations. Liberman and Yechiali (1978) consider customer cancellations in a 24-hour period. Orkin (1988) outlines some of the ideas behind revenue management for hotels and provides examples of the different types of calculations. Bitran and Mondschein (1995) model hotel reservations including multiple day stays, and Bitran and Gilbert (1996) extend previous models to incorporate uncertain arrivals.

See Table 1

Revenue management applies to the service industry when it meets the following five conditions (Kimes 2000), each specifically adapted for hotels.

1. Limited capacity. The design of revenue management target capacityconstrained services firms. The units of inventory sell in a short period of time with a fixed capacity, measured by the number of rooms.

2. Market segmentation. Service industries make use of segmentation because they can choose between different types of customers. They do not allow arbitrary price, so the service should have some characteristic that distinguishes it so that it uses the same unit of capacity to deliver many different services. Hotels usually use purchase restrictions and refund requirements to help segment the market between leisure and business customers.

3. Future demand is uncertain. Revenue management must have the ability to forecast the demand variability so that managers can increase prices during 
periods of high demand and decrease prices during periods of low demand. Hotels must set aside rooms for business customers, to protect them from the lower prices acquired by leisure customers before they know how many business rooms will sell.

4. Perishable units of inventory. Inventory distinguishes service firms from manufacturing firms. The units of inventory unsold after a specific date go to waste in service industries, because services cannot be stored. This special characteristic leads to the sale of services in advance. Hotels cannot store rooms for use by tomorrow's customer.

5. Appropriate cost and pricing structure. Many service firms have a fixed cost capacity expense and a demand that cannot rapidly adjust. In the same way the additional cost of adding a new customer to the available capacity is very low.

This paper studies revenue management models including group acceptance in hotels. Customer groups for hotels have their own set of characteristics that require a slightly different set of strategic levers from the typical approaches in use for the individual customer. Therefore, the study models the customer typology as an individual or as a group. The study tests a variety of different rooms' optimization algorithms, based on deterministic and stochastic programming techniques. The research intends to test a Decision Support Revenue Management (DSRM) system in a hotel chain and to identify factors associated with the management of different customer typologies.

The use of TM is needed in the hospitality industry for its survival, and evidence of this is shown in several studies. Donaghy el al. (1997) raised a 10-step model which stresses the use of TM in the segmentation of clients and the use of their characteristics 
in each market segment. Emeksiz et al. (2006) present a model in 5 steps comparanolo hotels using the TM and without it. It is also necessary to devise an asset to clients as long term. Therefore it is necessary to manage TM's revenue management with CRM systems, Noone et al. (2003), to ensure quality of service provided and the customer will be for a faithful future.

But it must be very careful when using different prices for the same service offered to customers. An example of this occurred in 2000, Enos (2000), when Amazon.com sold DVDs at different prices, and offering discounts between $20 \%$ and $40 \%$, as function of the geographic area in which the customer was applying for the product. The customers using ICTs and Internet could check for the same film different prices. The experiment created a negative impact on the company. In other sectors, such as the airline or hotel industry, price variations are higher and do not produce any negative perception by now. This is because the service is offered at different prices is well differentiated by their characteristics, so that the customer receives tangible differences in the products or services offered.

Six hotels in Andalusia (Spain) become the test sites of the proposed decision support system, implementing the DSRM system. These hotels are part of a 4-star hotel chain with an average of 160 bedrooms per hotel and with locations on the southern coast of Spain, a destination where the tourism industry is important at an international level, Guzman, Moreno and Tejada (2008). DSRM system focuses on Marbella Hotels. These hotels stay open year round, and the organization owns another hotel in Marbella. If necessary, guests can move from one hotel to another. This hotel chain obtains high customer satisfaction results, a necessary factor in service industries, Fullard (2007). Another paper related to such aspects but dealing with the airline industry has been addressed by Lindenmeier and Tscheulin (2008). 
Sections make up the remainder of the paper. Section 2 presents a new methodology used for tackling the problem in service industries. Section 3 addresses demand forecasting models that airlines traditionally use and its adaptation for the hotel sector. Section 4 presents the problem of optimizing room distribution. A new stochastic model is the basis of the problem, with or without groups' option. Section 5 describes a simulation model where it defines arrivals under three different policies for room inventory control. Section 6 discusses computational results and their comparisons. This section includes the comparison of performance indexes for heuristics, including occupancy rate, efficiency rate, and yield. Finally, Section 7 draws conclusions.

\section{Methodology}

Three management levels make up the DSRM system (Jones and Lockwood, 1998):

- Strategic level addresses the long-term and generally focuses at the head office. DSRM system data establishes market segmentation criteria and overall pricing policy in long-term, structural decisions.

- Tactical level deals with the intermediate-term running of individual operating units. DSRM system data establishes target occupancies for different market segments in the intermediate-term.

- Operational level concerns itself with the short-term conduct of the operating system, such as the sales office or the front desk. Human capital constitutes a key determinant of the operational office in service industries, Arribas and Vila (2007). DSRM system data decides what price to offer and what reservations to accept in the short-term. 
Following this structure we have proposed an original methodology described in the figure below, that features a brief description of architecture of the TRM system. Figure 1 introduces the key components and gives an overview of information flows, decision and design, and the test stage. Shoemaker (2003) also includes "tactical level" within the "strategic management", distinguishing the use of price changes in the hotel. Later sections describe in detail each DSRM system module.

\section{See Figure 1}

DSRM system follows four steps:

1. Demand forecasting must come from historical data. Based on occupation rates from historical data, the company can forecast future demand in a short-term period of time. The accuracy of forecasted demand is of special importance because it conditions the effectiveness of DSRM system. Frequent updates to historical data improve the accuracy of the model. Results from this module.

2. Optimal room distribution. The system uses forecasted data as an input to the application of the capacity models, so the forecasted quantity distributes among the different categories subject to the daily capacity of the hotel. A room distribution optimization model sets booking limits at diverse fare levels.

3. Room inventory control. Two differentiated phases make up this step: the arrival generation and the reservation system. First a simulation engine generates arrival processes of customers, whose data helps set up the arrival generation submodule within the room inventory control process. Conversely, the previously stated optimal room distribution process along with the arrival generation submodule are inputs for the reservation system submodule. The 
room inventory control process states the rooms' sell mode and the reservation system. The sales manager must receive the defined criterion to determine whether to accept or reject a request when a customer arrives.

4. Real assignment. As a final step, the sales office offers room prices to individual customers and negotiates rates for group customers with tour operators and travel agents.

Vinod (2004) raises a revenue management system applied to the hospitality industry stressing that the technology needs of each of the modules that comprise it. In the same line it can be address the importance of TM in revenue management techniques, Chiang, Chen and Xu (2007).

Historical data module updates automatically by incorporating data from sales and reservations. Also, data updates thanks to Internet and technology management, playing an important role in revenue and pricing management. These days customers have the capability to more easily compare prices among competitors, while service providers can get detailed information much quicker about customer behavior.

\section{Demand Forecasting}

Revenue management depends highly upon an accurate forecasting, needed for efficient reservation systems, and as input data for real-life oriented optimization models. For a comprehensive literature review on forecasting models see McGill and Van Ryzin (1999), Talluri and Van Ryzin (2004), Pai PF and Hong (2005) or Fernández-Morales and Mayorga-Toledano (2008).

The proposed DSRM system uses the customers' demand forecasting as an input to obtain an optimal allocation of rooms. Usually the system calculates demand forecasting from historical arrival information taking into consideration the length of the 
stay and room category. Different methods can work, from traditional approaches to advanced and/or combined booking models, Lee (1990).

Traditional forecasting techniques include moving average bookings, exponential smoothing, or ARIMA time series models amongst other well known statistical approaches, Makridakis, Wheelwright and Hyndman (1998). Advanced booking models predict customer pickup. They consider the incremental booking received during a certain time interval. Hybrid models include regression methods in which the independent variable is the number of reservations on hand for a particular day and the dependent variable is the economics parameters from customer countries taking the final number of rooms sold.

There is not an agreement on the best method. In fact, every hotel has its own particular characteristics, and a hotel may use a forecasting method depending on the time of year due to the strong seasonal component. In general, regression model, linear, or loglinear regression should provide dependable data. Unpublished studies use combination forecasting or specific methods as a pick-up model.

Group forecasts calculate the number of rooms available to individual guests. There are two types of group demands; ad hoc and series. Ad hoc groups consist of guests that are not regular in terms of repetition of travel patterns (dates and/or services). They use a specified number of rooms and services for specific nights. A typical ad hoc request might be a single or a few one-time rooms. Series groups typically stay longer and come from tour operators or travel agencies. These customers might request rooms in specific blocks of time or nights and reallocate them thru tour packages.

If the group forecast is not accurate, the total number of rooms available will be inaccurate, and the DSRM system proposals may lead to poor decisions. Inaccurate 
group forecasts have a greater impact during high occupancy periods of time. If group forecasts are too high, any mistake in the detection of such groups could lead to unused rooms. Unfortunately these rooms could sell to individual guests had there been prior knowledge instead of unnecessary waste. The experimental results section presents the results of the forecasting module for the different analyzed cases.

\section{Optimal Room Distribution}

Using the forecasting the guests' arrival, the system relies upon filling the available capacity by charging the highest price. This ensures that those customers most willing to pay for a room can do so. Most of the optimization models follow the Williamson (1992) models, maximizing revenue using a deterministic mathematical programming model and originally created for the airline industry. In the hotel industry, the objective is to allocate rooms to maximize revenue, while satisfying capacity constraints.

The optimal room distribution uses four models. The first is a deterministic model (DP), which accounts for the number of rooms in each category, taking into consideration individual guests only. The deterministic group problem (DGP) considers the DP scenario but also customer group arrivals. The system determines the opportunity cost due to the assignment of a set number of rooms to a group instead of individual customers. Individual customers usually pay more expensive rates than customer groups, but individual customers have a higher probability of no-shows, so there exists greater uncertainly of their arrivals.

The stochastic problem (SP) considers the possibility of an arrival differing from the mean, taking into account the natural variability of demand. The main problem corresponds with situations where there exist more requests than what appears as the mean value. In such cases, there are more customers willing to stay at the hotel than the 
expected amount. For these cases, the probability of customers accepting higher rates is greater than usual in deterministic models and therefore revenues would increase.

Afterwards, it presents a stochastic demand model including groups of customers; this is the stochastic group problem (SGP) which considers the SP problem plus group consideration.

To represent the mathematical formulation of the problem, Table 2 presents the data, parameters, and variables to deal with the different models to consider in the DSRM system, and those previously presented.

See Table 2

Once introducing Table 2, one can formulate the different models previously described (Figure 2).

See Figure 2

To formulate the models, one follows the next hypothesis. Data updates automatically in order to solve the model with the latest information. This leads to a situation where cancellations have a very low impact because the system incorporates eventual cancellations into the demand forecasting module varying the input data of the optimal room distribution module that has the ability to re-run. Additionally, the system does not account for overbooking. Overbooking occurs when a hotel accepts more reservations than available rooms. Depending on the country it could cause different legal issues when hotel managers use airline overbooking as a justification for the 
practice. However, the legal framework of the airline and the hotel industries differs. In actual practice hotels overbook less frequently than airlines.

Figure 2 presents the four models dealt with. First, the DP model attempts to maximize average profit per available unit by anticipating the price sensitivity of different customers and by anticipating the possibility of reserving a room for the customers willing to pay the highest price. The model selects a number of rooms the guest can reserve of $i j k$ characteristics, which stands for the arrival on day $i$, at a fare $j$, and for a stay of $k$ days. The constraints of the model include the daily capacity (in rooms) of the hotel and the expected demand.

Svrcek (1991) introduces an extension of the DP model including group reservation. Groups are special clients because they make bookings in advance, include blocks of rooms, and sometimes need conference rooms. Groups are also sensitive about price. In actual situations, tour operators or travel agents negotiate the group rate. During negotiation, tour operators contact the reservation supervisor requesting a specific number of rooms for a specific period of time. In addition, the group usually needs extra services such as food and beverages, conference rooms, etc. With these requests the hotel requires the minimum amount for a room to remain profitable in order to accept or reject decisions. Group requests can replace individual customers that could pay higher fares. Some group customers may occupy rooms with higher expected marginal revenue than other customers. However, the total group revenue may be higher than selling these rooms to individual customers.

DGP model maximizes the profitability of individual guests and customer groups. The model modifies the capacity constraint for the days expecting groups of customers. The hotel must have a large enough capacity to lodge such groups along 
with individual guests. The model uses a variable binary to accept or reject the group requests.

But in practice the demand is stochastic. Stochastic demand means that the number of allocated rooms could be different from the forecasted amount of requested rooms. The study considers a stochastic programming model, SP, with a simple resource problem. These particular stochastic problems do not cause severe computational difficulties, Kall and Wallace (1994). De Boer, Freling and Piersma (2002) introduce a stochastic model for the airline industry, assuming that discrete values are possible scenarios depending on customer demand.

Therefore, the model divides the number of rooms reserved $x_{i j k}$ into possible scenarios, that they rename as decision variables $x_{i j k, r}$. Such variables differ from zero when $x_{i j k, r-1}$ is equal to $d_{i j k, r-1}$, that is $\operatorname{Pr}\left(x_{i j k}=d_{i j k, r-1}\right)=\operatorname{Pr}\left(x_{i j k}=d_{i j k, r}\right)$. However, the sum of $x_{i j k, r}$ rooms sold to customers in $S$ scenarios must agree with the daily capacity constraint.

Following De Boer et al. (2002), the assumption is that three demand scenarios are enough to capture most of the extra revenue generated by excess customers. The forecasted mean calculates these demands by adding up and taking away the standard deviation. This generates a three-value band for every price.

Although the study presents a stochastic model for individual customers, we develop an original model for stochastic demand considering groups, SGP. This consideration does not appear in scientific literature thus far consulted. As an objective, the model searches for the better method for the assignment of rooms, taking into consideration the arrival of individual guests and customer groups, and accounting for the stochasticity of the demand. 
The individual customer demands must agree with the three bands previously discussed, and corresponding constraints states such consideration. Additionally, the daily capacity of the hotel must be sufficient enough to lodge the stochastic arrival of individual customers and groups.

Integer programming models make up all of the problems. However, the model can set the individual guests' variability to continuous due to the unimodularity property of the constraint coefficient matrix. Consequently, they can all reformulate as linear problems (cases of DP and SP) or mixed integer linear problems (cases of DGP and SGP), considering deterministic or stochastic demand depending on the model.

\section{Room inventory control}

In the previous section, the mathematical models allocated the finite rooms' inventory to the demand. The next step defines the operational work, when a customer requests a room. In such a situation, the reservation supervisor must decide whether or not to accept this guest. He/she must analyze the profit of reserving the room in that moment or waiting for another potential customer to arrive in a near future and pay a higher fare.

Below is a developed set of heuristics taking into account the acceptance or denial of such requests depending on a few parameters in the DSRM system developed.

See Figure 3

1. First-Come First-Serve (FC FS). This simple rule evaluates reservation request based on the well known first-come first-serve criterion. This rule disregards any room distribution. Whoever requests the room first gets the room. 
2. Distinct. This heuristic considers the protection of rooms according to the optimal room distribution proposed by the four models. The arrival simulation engine allows for the selection of the better solution from the four models in the simulation.

3. Nested. This method clusters the number of fare price into smaller buckets. Williamson (1992) proposes this method, suggesting a procedure to book rooms that considers higher fares and in turn utilizes the rooms reserved for the cheaper fare but charging the higher price. The highest fare price class has an inventory limit equal to the daily capacity.

Using a rolling horizon simulation of the reservation and a non-homogeneous Poisson arrival process they run tests using the three heuristic rules, suggested by Lewis and Shedler (1979) three decades ago, and still considered today a common basis for arrival generation. There is a comparison between the results of the of the heuristics simulations and a basic scenario case where they choose the arrival rate of individual customers function, $\lambda(t)$, from the historical daily pattern and positively correlates for fares (for example, the arrival rate of customers is higher during the afternoon than in the evening).

In the customer groups case, guests arrive in batches, instead of arriving one at a time. Using a discrete distribution that arranges successive batches into the sizes, they construct the arrival process of such groups. Also they create the number of each customer batch with a random variable.

\section{Results and discussion}

To test the suitability of the DSRM system, the experiment uses historical data from an actual Spanish hotel chain with six hotels on the southern coast of Spain. In the company, an analyst is responsible for making the daily decisions that are supported by 
the DSRM system, and a sales team responsible of checking the outputs of the system, using such information to deal with groups and negotiate prices.

The company provides historical data that is the input information needed for the demand forecasting module. The company carries out the forecasting for a 30 dayrolling-horizon because a month is considered by the company mangers as the longer horizon including reliable data to be forecasted and planned. The forecasting shows how great volatility makes it extremely difficult to achieve accurate forecasts.

They use the forecasted demand for each day to obtain the optimal room distribution, considering the four mathematical models: DP, DGP, SP, SGP. Each of them produces a different proposal that the DSRM system considers. Models work using CPLEX 8.0.

They consider a target hotel of 200 available rooms because it represents the standard hotel of the company. The interval $[0,21]$ randomly generates the length of the stay, $k$ in mathematical models. Individual guests have the ability to book at five different fares, which Table 3 describes.

See Table 3

For the stochastic models, they take into account three different scenarios: low track line, average, and high track line. It corresponds to the $r=1, \ldots, S$ in the models. Following De Boer et al. (2002) we set a probability for each scenario equal to $p_{1}: 0.8$ / $0.6 / 0.4 ; p_{2}: 0.6 / 0.4 / 0.2$ and $p_{3}: 0.7 / 0.5 / 0.3$.

The arrival of customers provided by the demand forecasting module corresponds to the daily arrival. Therefore they must distribute this value thru the day 
by hours. They carry out this distribution by using a simulation engine based on ARENA simulation software.

These arrivals are a non-homogeneous Poisson process with an arrival rate $\lambda(t)$ depending on the time. They construct an actual daily pattern by taking into account the expert opinion of the people in-charge in the hotel chain.

The reservation system uses the arrival generation together with the four proposals from the optimal room distribution to propose the room assignments. To do so the systems use FC FS, distinct and nested heuristics for the four proposals from the optimal room distribution. The DSRM system must analyze and compare twelve different proposals.

The expected incomes from the twelve alternatives are compared among them and with a value referred to as "real optimum distribution". Such real optimum distribution corresponds to better distribution after analyzing the "a posteriori" actual overall number of customer arrivals knowing all the information.

The following expressions calculate the percentages of occupancy, efficiency, and yield:

$$
\begin{gathered}
\text { Occupancy }=\frac{\text { number of rooms occupied }}{\text { maximum daily capacity }} \times 100 \\
\text { Efficiency }=\frac{\text { number of customers accepted }}{\text { total number of rooms }} \times 100 \\
\text { Yield }=\frac{\text { actual rooms income }}{\text { potential rooms income }} \times 100
\end{gathered}
$$

Yield rate indicates the real incomes with respect to the maximum possible income assuming all of the rooms sell at the full rack rate.

Table 4 shows the average results for a 30 days period and the twelve alternatives, also they compare with the real optimum distribution. It contains the 
obtained average daily incomes, sorted by capacity distribution model, and the room assignment method for a non-homogeneous Poisson process.

See Table 4

As noted in Table 4, the best room distribution is a combination of group models (DGP/SGP) with assignment rule based on nested heuristic. The results of such a combination show an average error of less than 5\% with respect to the actual optimal distribution. On the contrary, models not based on customer groups consideration report errors higher than an average of $8 \%$, nearly 3,000 Euros daily. Also, the efficiency, occupancy, and yield factors reveal the convenience of such an approach because it provides more adjusted rates. In fact, group consideration is of higher importance when considering the groups of customers.

However, it requires a detailed analysis. To do so, one must consider Figures 4 and 5, which include the daily analysis. They consider the results for the four performance indexes: incomes, occupancy, efficiency, and yield. The figures analyze such results with respect to the optimal room distribution models (Figure 4) and with respect to room inventory control heuristic rules (Figure 5).

See Figure 4

See Figure 5 
Figure 4 depicts the daily evolution of the four indexes with respect to the four different optimal room distribution mathematical models. DGP and SGP (group models) lines are always on top of the DP and SP lines that consider only individual customers. Most of the time DGP performs better. It is mainly due to the consideration of all of the typologies of customers, and this allows for a better adaptation to the demand and the behavior of customers. However, some days show poorer results due to no-shows. For example, refer to day 6 in the figure.

Also, the deterministic approaches show better performance related to the occupancy, efficiency, and yield rates. The difference between deterministic and stochastic models is the expected value of perfect information, EVPI. It shows how much one could expect to earn if one were told what would happen before making one's decision. It measures the value of randomness, but it does not show that the deterministic models are dysfunctional. A small EVPI means that randomness will play a minor role in the model, whereas with a large EVPI randomness plays a major role.

Despite this, the stochastic model considering groups (SGP) obtained very good results regarding incomes, although not as good as the deterministic model, DGP. After analyzing the global behavior, one can see that the deterministic group room distribution model presents the best alternative of the analyzed options.

Figure 5 presents the daily evolution of the four performance indexes related to the three assignment heuristics of the room inventory control. Generally, the nested line shows the better performance. However, the distinct method sometimes provides better assignments. It is the case between days 4 to 10 approximately. It due to the fact that ultimately they do not reach expected demand. Consequently, many rooms were not sold to first-come first-serve customers, mainly economy fare customers. Ultimately the 
rooms remain empty. The FC FS method is a basis method when one does not take action for distributing rooms. This method shows has a worse trend than the others. The global behavior leads to the recommendation of the nested method as the best alternative.

Figures 4 and 5 allow observing the daily evolution as function of the optimal room distribution models and the assignment heuristics. This analysis goes beyond the average results shown in Table 4 depicting daily limit situations that allows analysis based on maximum and minimum deviations and not only on average results.

The final interesting parameter of the models considered is the computational time. The models run on a PC Pentium IV 3GHz with 2Gb RAM memory, and use CPLEX 8.0 as optimization software. All tested approaches obtain feasible times, all executed in less than 5 seconds. Table 5 summarizes the computational times related to the average time, maximum and minimum times, and standard deviations.

See Table 5

\section{Conclusions and further research}

In this paper, we present a Decision Support Revenue Management System as a sophisticated technology helping managers to make decisions in the framework of the hotel industry. The situation presented corresponds to an inventory perishable problem under limited capacity, which price policies differentiate.

The DSRM system includes a demand forecasting module to estimate the arrival of customers from historical data, an optimal room distribution based on mathematical models to distribute the forecasted demand into different categories subject to the daily 
capacity of the hotel, a room inventory control module consisting of an arrival generation and a reservation system, and finally a real assignment module helping the sales office to offer room prices to individuals and group customers.

Literature on group customers is scarce by and less agreeable. First, we consider a special case for the problem, which models as deterministic programming. Then, we use stochastic programming to solve the same case. The consideration of such a customer groups model is an original idea in the scientific literature dealing with the hotel industry.

We experiment with several models. The analysis of the experimental results concludes that the room distribution based on group models together with a nested inventory control assignment method provides the best results.

This DSRM system needs a special implementation of IT department. It is special in the sense that it is based on particular models that are highly data-fragile. This system will not perform in good order without data or not worth gathering data, and then the system would not perform correctly. DSRM system needs data collected at lowest level and stored for a relative long time in operational databases. The DSRM system follows a wide spectrum of technology management focusing on planning, organizing, staffing, implementing, and monitoring and evaluating stages oriented on how to use technology to gain profit.

The proposed DSRM system provides a suitable alternative for the management of any inventory perishable problem under limited capacity, concretely for every hotel located in every place of the world. Although some hotel chains usually focuses its energy on selling rooms (volume of sales), in some occasions not making a sale could be more suitable, because it could increase revenues. In fact, this revenue objective can lead to lower room sales. The DSRM system takes into account such aspects, and 
although the sales team could be recommending increases of room sales at their own discretion, DSRM system would be preventing from offering discounts to wait customers willing to pay more in a near future.

In terms of future work we are focusing this approach on many other service industries, in which this system can adapt considering their particular characteristics. Another issue we are analyzing is to conceive group auction setting. Other functional areas of the company as pricing analysts and product-design groups will be involved. In this way, we are exploring different alternatives of price negotiations among travel agencies, tour operators, and hotels owners. In this way, customer behavior and demand models based on individual customer choice, random-utility models, and aggregate market-demand, product interactions with demand for other products and dependence on historical products attributes incorporated in its specification, Konecnik and Gartner (2007).

Another limitation of this system is concerned with knowledge management. It is necessary improve information process that allow for an extensive use of knowledge transfer, knowledge reuse, storage and production of knowledge. Hallin and Marnburg (2008) have recently suggested new lines to explore such aspects.

\section{Acknowledgements}

We would like to acknowledge the financial support given by the Ministerio de Educación y Ciencia (project ref. DPI2005-09132-C04-01), Spain.

\section{References}

Arribas I, Vila J. Human capital determinants of the survival of entrepreneurial service firms in Spain. International Entrepreneurship and Management Journal 2007; 3: 309-322. 
Belobaba P, Weatherford L. Comparing Decision Rules that Incorporate Customer Diversion in Perishable Asset Revenue Management Situations. Decision Sciences 1996; 27: 343-363.

Bitran G, Gilbert S. Managing Hotel Reservations with Uncertain Arrivals. Operations Research 1996; 44: 35-49.

Bitran G, Mondschein S. An Application of Yield Management to the Hotel Industry Considering Multiple Day Stays. Operations Research 1995; 43 (3): 427-443.

Bodily S, Weatherford L. Perishable-asset revenue management: generic and multipleprice yield management with diversion. Omega 1995; 23 (2): 173-185.

Chiang W-C, Chen J, Xu X. An overview of research on revenue management: current issues and future research. Int. J. Revenue Management 2007; 1 (1): 97-128.

Choi S, Mattila S. Impact of information on customer fairness perceptions of hotel revenue management. Cornell Hotel and Restaurant Administration Quarterly 2005; 46: 444-451.

De Boer S, Freling R, Piersma N. Mathematical programming for network revenue management revisited. European Journal of Operational Research 2002; 137: 7292.

Donaghy K, McMahon-Beattie U, McDowel D. Implementing Yield Management: lessons from the Hotel Sector. International Journal of Contemparary Hospitality Management 1997; 9 (2): 50-54.

Emeksiz M, Gursoy D, Icoz O. A Yield Management Model for Five-star Hotels: Computerized and Non-computerized Implementation. International Journal of Hospitality Management 2006; 25: 536-551.

Enos L. Amazon apologizes for pricing blunder. E-Commerce Times 2000; Sept 28. 
Fernández-Morales A, Mayorga-Toledano MC. Seasonal concentration of the hotel demand in Costa del Sol: A decomposition by nationalities. Tourism Management 2008; 29: 940-949.

Fullard F. A model to evaluate the effectiveness of enterprise training programs. International Entrepreneurship and Management Journal 2007; 3: 263-276.

Guzman J, Moreno P, Tejada P. The tourism SMEs in the global value chains: the case of Andalusia. Service Business 2008; 2: 187-202.

Hallin CA, Marnburg E. Knowledge management in the hospitality industry: A review of empirical research. Tourism Management 2008; 29: 366-381.

Jones P, Lockwood A. Operations Management Research in the Hospitality Industry. International Journal Hospital Management 1998; 17 (2): 183-202.

Kall P, Wallace S. Stochastic Programming, John Wiley \& Sons; 1994.

Kimes S. A Strategic Approach to Yield Management. In: Ingold, A., McMahonBeattie, U., Yeoman, I., Yield Management: Strategies for the service industries, Contiuum, London 2000: 3-14.

Konecnik M, Gartner WC. Customer-based brand equity for a destination. Annals of Tourism Research 2007; 34 (2): 400-421.

Liberman V, Yechiali U. On the Hotel Overbooking Problem. Management Science 1978; 24: 1117-1126.

Lee A. Airline Reservations Forecasting: Probabilistic and Statistical Models of the Booking Process. Massachusetts Institute of Technology, M.I.T. Libraries Theses Collection; 1990.

Lee S M, Ribeiro D, Olson D L, Roig S. The importance of the activities of service business in the economy: welcome to the Service Business. An International Journal. Service Business 2007; 1 (1): 1-5. 
Lewis P, Shedler G. Simulation of Nonhomogeneous Poisson Processes by Thinning. Naval Research Logistics Quarterly 1979; 26: 403-413.

Lindenmeier J, Tscheulin DK. The effects of inventory control and denied boarding on customer satisfaction: The case of capacity-based airline revenue management. Tourism Management 2008; 29: 32-43.

Smith B, Leimkuhler J, Darrow R. Yield Management at American Airlines. Interfaces 1992; 22 (1): 8-31.

Makridakis S, Wheelwright SC, Hyndman RJ. Forecasting: Methods and Applications. John Wiley and Sons; 1998.

McGill J, Van Ryzin G. Revenue Management: Research Overview and Prospects. Transportation Science 1999; 33 (2): 233-256.

Noone BM, Kimes SE, Renaghan LM. Integrating Customer Relationship Management and Revenue Management: a Hotel Perspective. Journal of Revenue and Pricing Management 2003; 2 (1): 7-22.

Orkin E. Boosting Your Bootom Line with Yield Management. Cornell Hotel and Restaurant Administration Quarterly 1988; 28 (4): 52-56.

Pai PF, Hong WC. An Improved Neural Network Model in Forecasting Arrivals. Annals of Tourism Research 2005; 32 (4): 1138-1141.

Shoemaker S. Future of Revenue Management: the Future of Pricing in Services. Journal of Revenue and Pricing Management 2003; 2 (3): 271-279.

Smith B, Leimkuhler J, Darrow R. Yield Management at American Airlines. Interfaces 1992; 22 (1): 8-31.

Svrcek T. Modeling Airline Group passenger Demand for Revenue Optimization. Massachusetts Institute of Technology, M.I.T. Libraries Theses Collection 1991. 
Talluri K, Van Ryzin G. The Theory and Practice of Revenue Management. Kluwer Academic Publishers; 2004.

Vinod B. Unlocking the Value of Revenue Management in the Hotel Industry. Journal of Revenue and Pricing Management 2004; 3 (2): 178-190.

Williamson E. Airline Network seat inventory control: Methodologies and revenue impacts. Massachusetts Institute of Technology, M.I.T. Libraries Theses Collection; 1992. 
Table 1. Reference Summary in Hotels

\begin{tabular}{l|l}
\hline \multicolumn{1}{c|}{ Industry } & \multicolumn{1}{c}{ Reference } \\
\hline \multirow{5}{*}{ Hotels } & Rothstein (1974), Ladany (1976), Liberman \& Yechiali \\
& (1978), Orkin (1988), Relihan (1989), Kimes (1989), Bitran \\
& \& Gilbert (1992), Bitran \& Mondschein (1995), Baker \& \\
& Collier (1999), Jones (1999), Luciani (1999), Choi \& Cho \\
& (2000), Withiam (2001), Noone et al. (2003), Vinod (2004), \\
& Choi \& Mattila (2005), Emeksiz et al. (2006), Hallin (2008) \\
\hline
\end{tabular}


Table 2

List of parameters and variables of the models considered for optimizing the room distribution in the DSRM system

\begin{tabular}{|c|c|c|c|c|}
\hline \multicolumn{3}{|c|}{$\overline{\text { DP }}$} & \multicolumn{2}{|c|}{ DGP $^{a}$} \\
\hline \multirow{4}{*}{ صَّ } & $k$ & Length of stay (in days) & $\lambda_{g}$ & Length of group stay (in days) \\
\hline & $p_{j}$ & Fare price (category $j$ ) & $\mu_{g}$ & Group size (customers) \\
\hline & $b_{i}$ & Hotel capacity on day $i$ & & \\
\hline & $d_{i j k}$ & $\begin{array}{l}\text { Forecasted demand on day } i \text {, staying } k \text { days } \\
\text { at fare category } j \text {. }\end{array}$ & $c_{g}$ & Fare group \\
\hline 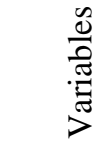 & $x_{i j k}$ & $\begin{array}{l}\text { Integer variable. Number of rooms reserved } \\
\text { for the guest of } i j k \text { characteristics (arrival day } \\
i \text {, fare } j \text { and length of stay } k \text { ) }\end{array}$ & $x_{g}$ & $\begin{array}{l}\text { Binary variable. It represents } \\
\text { the possible acceptance of } \\
\text { group, } g \text {. }\end{array}$ \\
\hline \multicolumn{5}{|c|}{ SP / SGP ${ }^{a, b}$} \\
\hline 苂 & $\begin{array}{l}r \\
d_{i j k, r}\end{array}$ & \multirow{2}{*}{\multicolumn{3}{|c|}{$\begin{array}{l}\text { Number of alternative scenarios being considered depending on different customers' } \\
\text { arrival process. It varies from } 1 \text { to } S \\
\text { Forecasted demand on day } i \text {, staying } k \text { days at fare category } j \text { according to scenario } r \text {. } \\
\text { Demand taken from a discrete set of values }\left\{d_{i j k, 1}<d_{i j k, 2}<\ldots<d_{i j k, r}\right\}\end{array}$}} \\
\hline & $D_{i j k}$ & & & \\
\hline 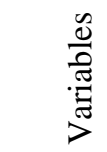 & $x_{i j k, r}$ & \multicolumn{3}{|c|}{$\begin{array}{l}\text { Integer variable. It represents the part of the demand } D_{i j k} \text { falling into the interval } \\
\left(d_{i j k, r-1}, d_{i j k, r}\right]\end{array}$} \\
\hline
\end{tabular}

${ }^{a}$ In DGP and SGP problems, subscript $i^{*}$ means the arrival of a group on day $i^{*}$ at difference from the subscript,$i$, applicable to arrivals of individual customers.

${ }^{\mathrm{b}} \mathrm{SP}$ considers the same set of data and variables in problem DP plus those specific for stochastic problems at the box below. The same happens with respect to SGP and DGP problems. 
Table 3. Individual Price Classes

\begin{tabular}{|l|c|}
\hline \multicolumn{1}{|c|}{ Class } & Price \\
\hline Premiere / Luxury fare & $250 €$ \\
\hline Business / Superior fare & $175 €$ \\
\hline Standard / Normal fare & $125 €$ \\
\hline Economy / Discount fare & $90 €$ \\
\hline Supereconomy / Superdiscount fare & $75 €$ \\
\hline
\end{tabular}


Table 4

Comparison of average results

\begin{tabular}{|c|c|c|c|c|c|}
\hline & & $\overline{D P}$ & DGP & SP & SGP \\
\hline FC FS & $\begin{array}{l}\text { Incomes } \\
\text { Occupancy } \\
\text { Efficiency } \\
\text { Yield }\end{array}$ & $\begin{array}{r}20,670.70 \\
65.0 \% \\
78.2 \% \\
59.1 \% \\
\end{array}$ & $\begin{array}{r}22,837.50 \\
69.8 \% \\
86.4 \% \\
65.3 \% \\
\end{array}$ & $\begin{array}{r}20,670.70 \\
65.0 \% \\
78.2 \% \\
59.1 \% \\
\end{array}$ & $\begin{array}{r}22,837.50 \\
69.8 \% \\
86.4 \% \\
65.3 \%\end{array}$ \\
\hline DISTINCT & $\begin{array}{l}\text { Incomes } \\
\text { Occupancy } \\
\text { Efficiency } \\
\text { Yield }\end{array}$ & $\begin{array}{r}21,881.04 \\
67.7 \% \\
82.8 \% \\
62.5 \% \\
\end{array}$ & $\begin{array}{r}24,150.00 \\
62.6 \% \\
91.4 \% \\
69.0 \% \\
\end{array}$ & $\begin{array}{r}22,023.43 \\
68.0 \% \\
83.3 \% \\
62.9 \% \\
\end{array}$ & $\begin{array}{r}24,386.25 \\
63.1 \% \\
92.3 \% \\
69.7 \% \\
\end{array}$ \\
\hline NESTED & $\begin{array}{l}\text { Incomes } \\
\text { Occupancy } \\
\text { Efficiency } \\
\text { Yield }\end{array}$ & $\begin{array}{r}22,782.86 \\
69.6 \% \\
86.2 \% \\
65.1 \% \\
\end{array}$ & $\begin{array}{r}25,278.75 \\
65.1 \% \\
95.6 \% \\
72.2 \% \\
\end{array}$ & $\begin{array}{r}22,972.71 \\
60.0 \% \\
86.9 \% \\
65.6 \% \\
\end{array}$ & $\begin{array}{r}25,291.88 \\
65.1 \% \\
95.7 \% \\
72.3 \% \\
\end{array}$ \\
\hline ROD $^{a}$ & Incomes & $23,732.14$ & $26,250.00$ & $23.732,14$ & $26,250.00$ \\
\hline
\end{tabular}

${ }^{a}$ Supposed real optimum distribution after real requesting by customers 
Table 5

Comparison of computational times (in seconds)

\begin{tabular}{|c|cccc|}
\cline { 2 - 5 } \multicolumn{1}{c|}{} & Average time & $\begin{array}{c}\text { Maximum } \\
\text { time }\end{array}$ & $\begin{array}{c}\text { Minimum } \\
\text { time }\end{array}$ & $\begin{array}{c}\text { Standard } \\
\text { Deviation }\end{array}$ \\
\hline DP & 0.91 & 2.45 & 0.51 & 0.65 \\
DGP & 1.41 & 2.25 & 0.93 & 0.42 \\
SP & 2.45 & 3.06 & 1.85 & 0.38 \\
SGP & 3.65 & 4.81 & 2.70 & 0.66 \\
\hline
\end{tabular}


Figure 1

Decision Support Revenue Management System process flow

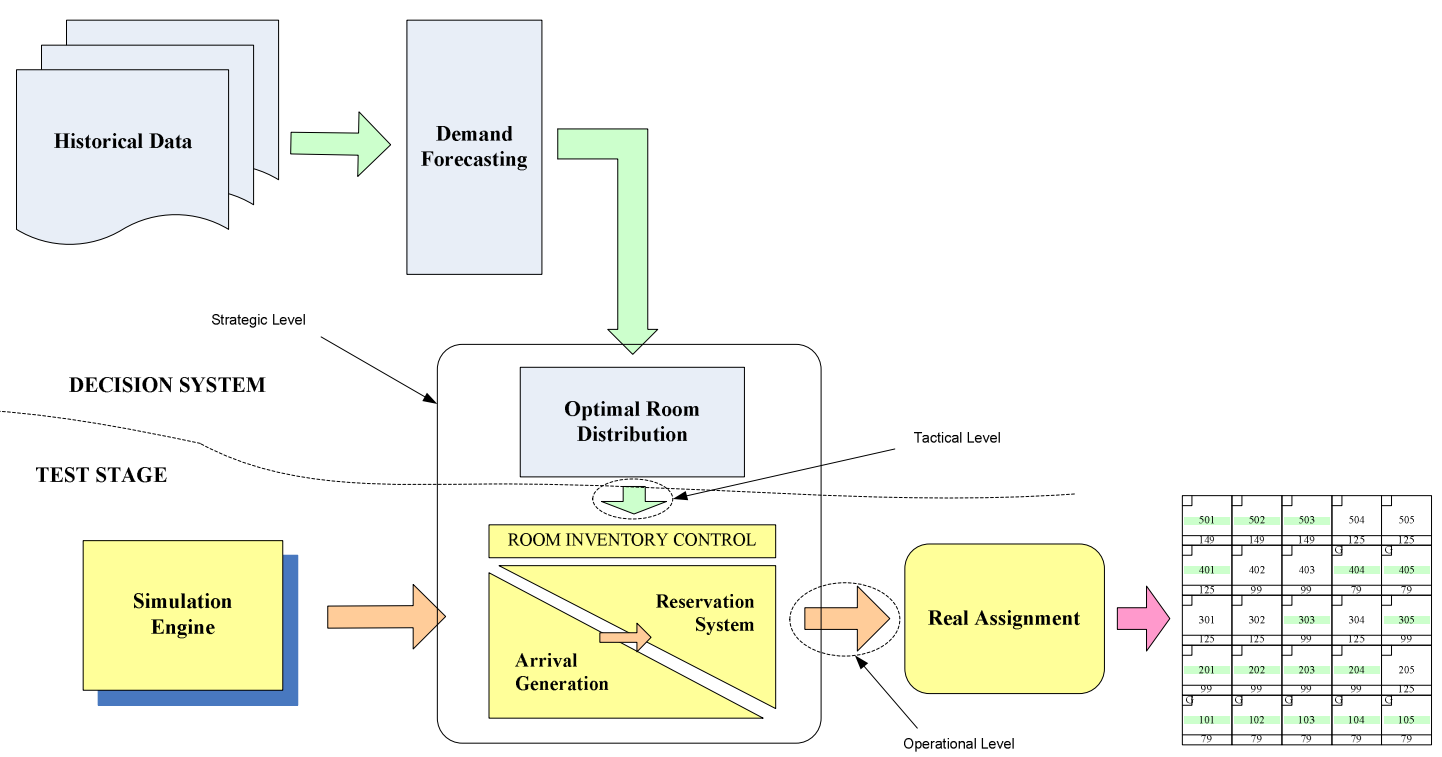


Figure 2

\section{Optimal room distribution models}

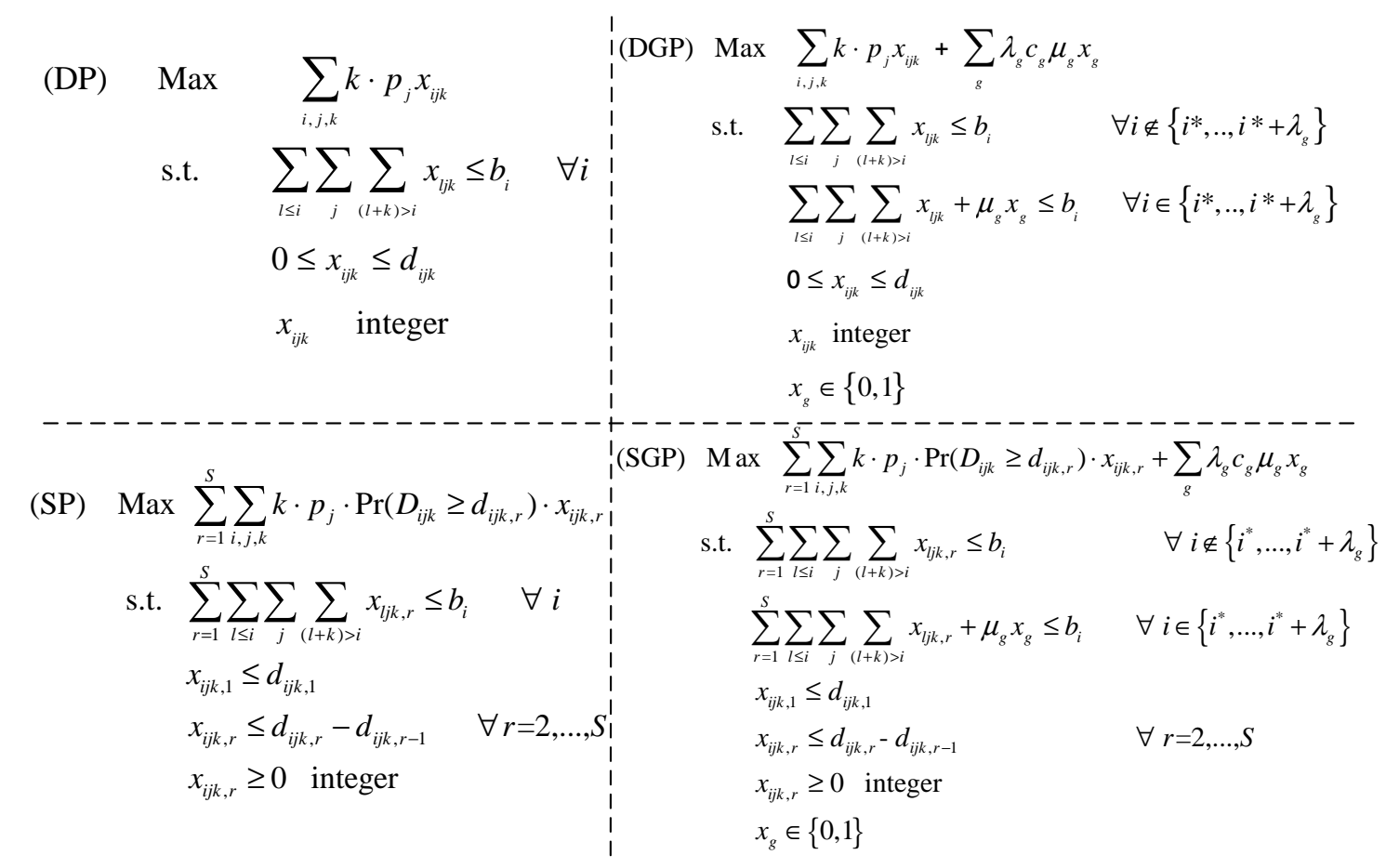


Figure 3

Heuristics of room inventory control

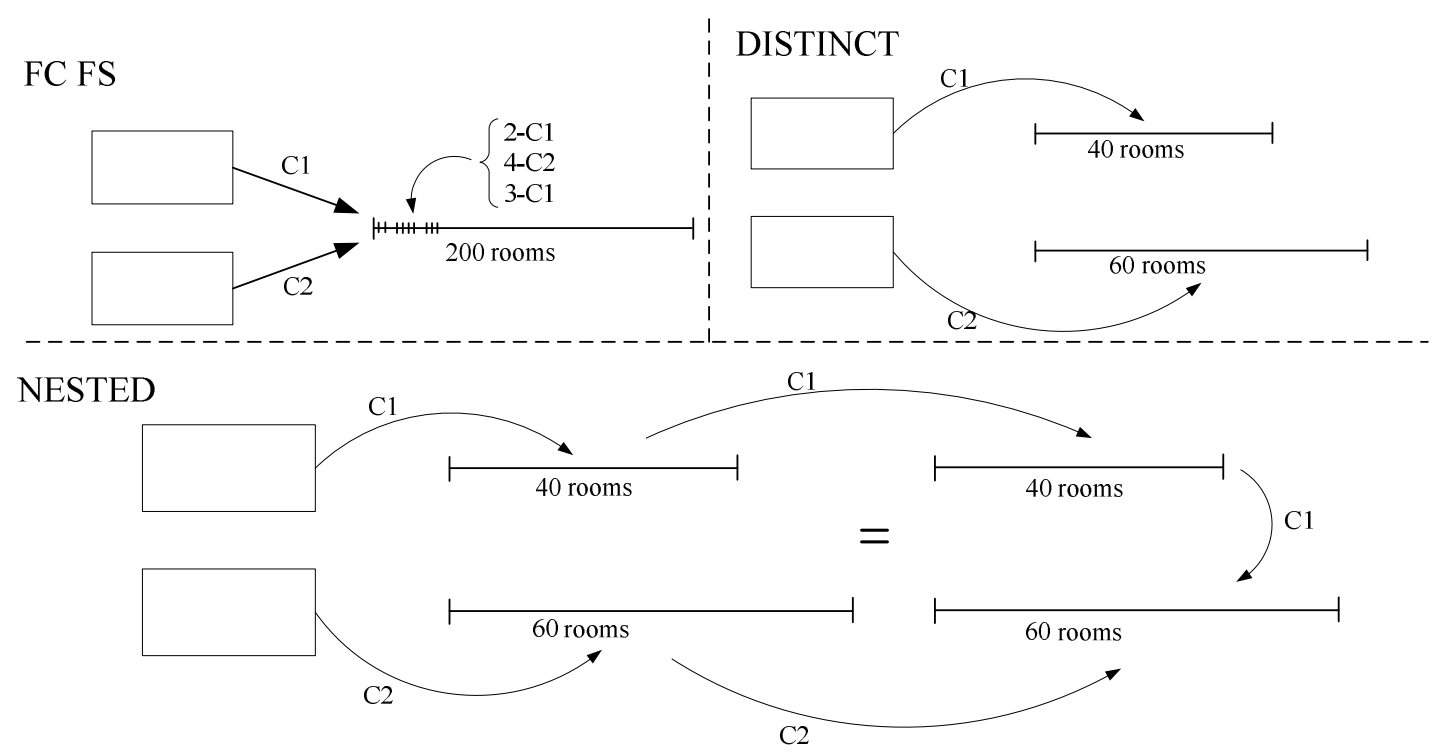

